\title{
Successful repair of pulmonary atresia with ventricular septal defect without the use of a conduit: a new surgical option
}

\section{Report of two cases}

\author{
Zohair Al-Halees, Omar Galal, Neil Wilson
}

\begin{abstract}
A new technique for the restoration of continuity between the pulmonary artery and the right ventricle in pulmonary atresia with ventricular septal defect without the use of a conduit is described. This was accomplished by anastomosing the inferior margin of the distal pulmonary artery to the apex of a T-shaped infundibular ventriculotomy to form the posterior wall of the reconstructed right ventricular outflow tract. A winged patch of bovine pericardium was then used for the anterior wall to complete reconstruction of the transannular right ventricular outflow tract. This technique was used successfully in two patients.
\end{abstract}

(Br Heart J 1992;68:320-2)

The term pulmonary atresia with ventricular septal defect is sometimes used to designate the extreme form of tetralogy of Fallot. The intracardiac anatomy of these patients is similar to that seen in tetralogy of Fallot. ${ }^{1}$

Surgical management has tended to be along the same lines as that of tetralogy of Fallot: the atrial and ventricular defects are closed, all extracardiac sources of pulmonary arterial blood supply excluded, and right ventricle to pulmonary artery continuity restored. This must result in an acceptable peak systolic pressure ratio between the right and left ventricles (usually less than $0 \cdot 85$ ). ${ }^{23}$ Generally, a conduit is needed to establish right ventricle to pulmonary artery continuity in pulmonary atresia.

All conduits are liable to progressive stenosis, and valve failure if a valved conduit is used. ${ }^{34}$ The use of homografts reduces these inherent problems but does not eliminate them. ${ }^{5}$ The availability of homografts is a problem in many parts of the world, including Saudi Arabia. Therefore, there are advantages in accomplishing a repair without conduits whenever feasible.

\section{Patients and methods}

PATIENT 1

An 11 year old boy with pulmonary atresia and ventricular septal defect was palliated in infancy by bilateral Blalock-Taussig shunts and ligation of multiple aortopulmonary collaterals.

Cardiac catheterisation showed good sized confluent pulmonary arteries, a non-function-
Department of Cardiovascular Diseases, King Faisal Specialist Hospital and Research Centre Riyadh, Saudi Arabia Z Al-Halees

O Galal

$\mathrm{N}$ Wilson

Correspondence to Mr Zohair Al-Halees, FRCS(C), MBC 16, King Faisal Specialist ing Faisal Specialist Riyadh 11211, Saudi Arabia. Accepted for publication 29 November 1991.

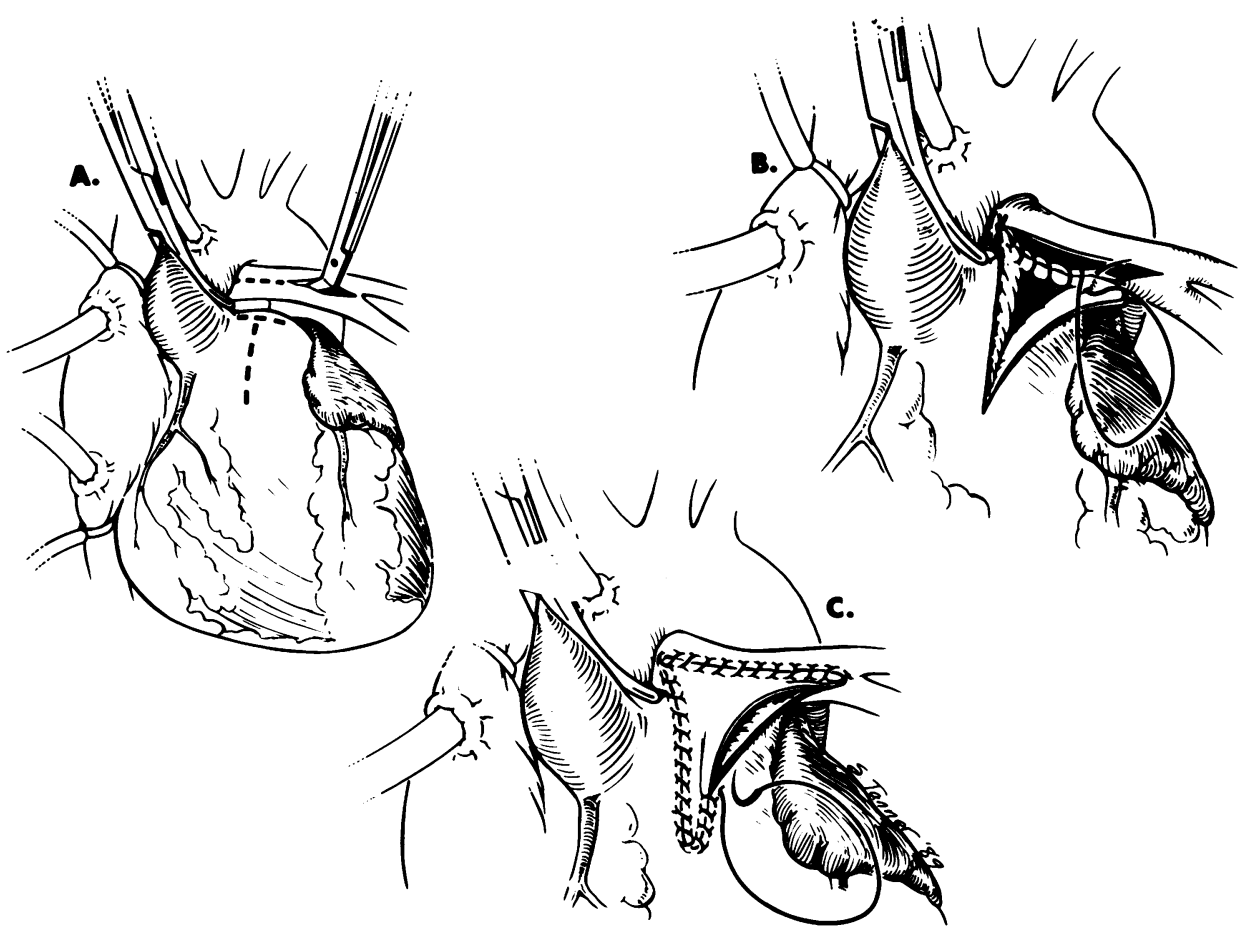

Figure 1 Surgical technique. 


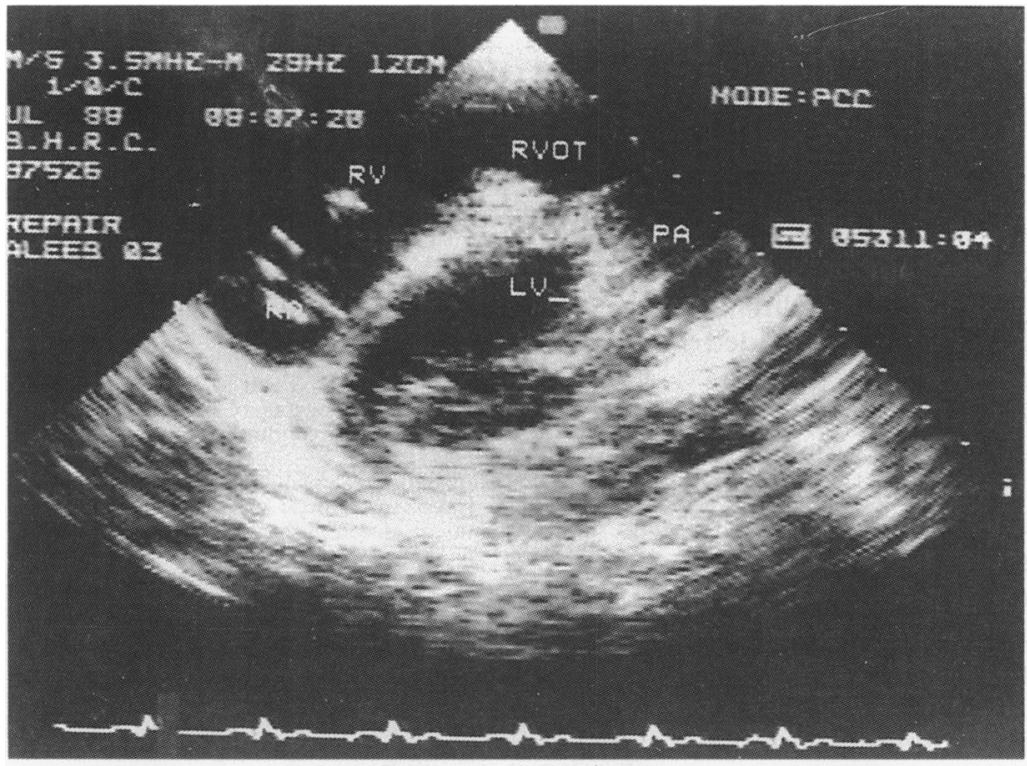

Figure 2 Echocardiogram of the right ventricular outflow tract (RVOT) after repair. Note the widely patent right ventricular outflow tract $(R V O T) . R V$, right ventricle; $L V$, left ventricle; $P A$, pulmonary artery.

ing left Blalock-Taussig shunt, and two large aorta to right pulmonary artery collaterals with a functioning right Blalock-Taussig shunt.

At surgery the right Blalock-Taussig shunt and the collaterals were ligated and divided The ventricular septal defect was closed with a patch of bovine pericardium. Right ventricle to pulmonary artery continuity was established by the technique shown in fig 1 .

PATIENT 2

A 3 month old boy presented with cyanosis since the early weeks of life and was found to have pulmonary atresia and ventricular septal defect with a patent ductus arteriosus.

At surgery there was an atretic main pulmonary artery that reached the right ventricle as a fibrous cord. The branch pulmonary arteries were confluent. The patent ductus arteriosus was ligated and the septal defect was closed with a patch of bovine pericardium and right ventricle to pulmonary artery continuity was established by the technique shown in fig 1 .

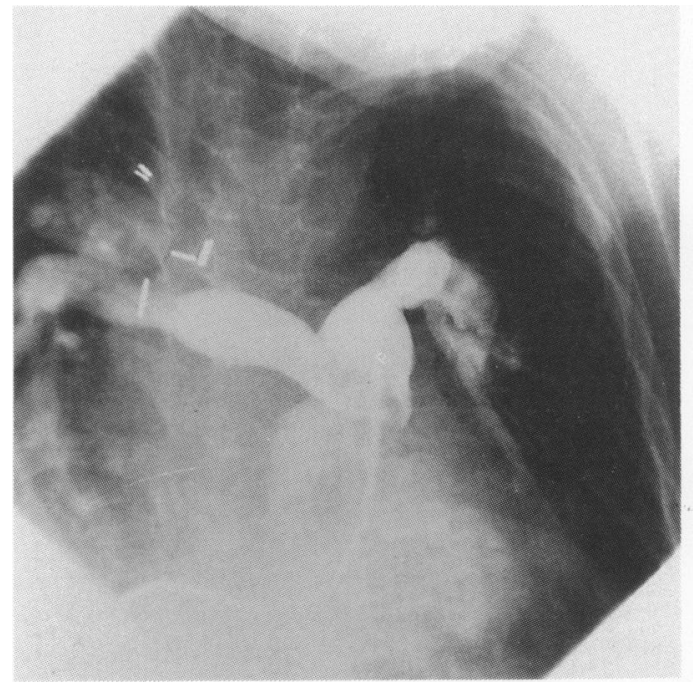

Figure 3 Angiogram of the right ventricular outflow tract pulmonary arteries in patient 1.

\section{Surgical technique}

The pulmonary arteries were widely freed to the hila of both lungs to allow good mobility. Any systemic to pulmonary artery shunts were divided and not just ligated. A patent ductus or a ligamentum arteriosum was divided. A Tshaped right ventriculotomy was made in the outflow tract. Through the ventriculotomy, infundibular obstruction was relieved and the ventricular septal defect closed. The confluence of the pulmonary arteries was opened longitudinally (fig 1A). The inferior margin of the pulmonary arteriectomy was pulled down and anastomosed to the apex of the right ventriculotomy to form the posterior wall of the reconstructed right ventricular outflow tract (fig 1B). A wide winged patch of bovine pericardium was used to construct the anterior wall to complete the repair (fig 1C).

\section{Results}

Postoperatively there were no specific complications related to the technique in either patient. The right ventricle/left ventricle systolic pressure ratio in both patients before discharge from the intensive care unit was 0.6 , as measured on pullback of a pulmonary artery catheter placed at the time of surgery. Before discharge from the hospital echocardiography showed no residual right ventricular outflow tract obstruction or ventricular shunt (fig 2).

On follow up 18 months later both patients were doing well. Patient 2 was symptom free and did not require medical treatment. Patient 1 was in right heart failure and required digoxin, captopril, and diuretics. Because of concern about right heart failure cardiac catheterisation was repeated. This showed a widely patent right ventricular outflow tract without residual gradient (fig 3). There was no residual ventricular septal defect and the right ventricle/left ventricle pressure ratio was $0 \cdot 6$. There was free pulmonary regurgitation. The right ventricular function was mildly impaired.

\section{Discussion}

The long-term effects of pulmonary valve insufficiency on right ventricular function after repair of tetralogy of Fallot are still unclear. Experience has established that the right ventricle can function very well without a pulmonary valve for a long period. Unsatisfactory results and late deaths are related to residual right ventricular hypertension rather than pulmonary regurgitation. ${ }^{67}$

This picture encouraged us to extend the experience with a transannular patch repair of tetralogy of Fallot to some patients with favourable anatomy who had pulmonary atresia and a ventricular septal defect who otherwise would require a conduit. This same principle of repair was successful in a patient with truncus arteriosus ${ }^{8}$ and in anatomical repair of abnormalities of ventriculoarterial connection associated with a ventricular septal defect. $^{9}$ 
The technique we used to some extent simplifies the surgical total repair of pulmonary atresia with ventricular septal defect. It can be applied in many patients considered for total repair. In some, however, mobilisation of pulmonary arteries is difficult and in addition the gap between the pulmonary artery confluence and the right ventricle is large. For this reason we attempted full mobilisation of the pulmonary arteries to the hila of the lungs and divided collateral arteries and surgically placed shunts or a patent ductus arteriosus. In some cases, however, safe approximation of the pulmonary artery to the right ventricle will not be possible and a conduit will be required. In addition the left anterior descending coronary artery may limit the extent of the $T$-shaped ventriculotomy. Fortunately we avoided this potential complication, but we think that in many cases a vertical incision could still be manipulated to a horizontal orifice to allow anastomosis with the lower extremity of the pulmonary artery.

Because the postoperative course and the functional state of both patients during 18 months of follow up was acceptable we are reasonably optimistic that the long-term course of these patients may be similar to the long term results of repair tetralogy of Fallot. World wide experience with the repair of tetralogy of Fallot is well known and is generally good. ${ }^{710}$

1 Agaraval KC, Edwards WD, Puga FJ, Mair DD. Acute postoperative obstruction of extracardiac conduit due to postoperative obstruction of extracardiac conduit due to
separation of thin fibrous peel. Mayo Clinic Proc 1982; 57:189-91.

2 Bharati S, Paul MH, Idriss FS, Potkin RT, Lev M. The surgical anatomy of pulmonary atresia with ventricular septal defect: Pseudotruncus. J Thorac Cardiovasc Surg 1975;69:713-21.

3 Chem DH, Moller JH. Comparison of late clinical status between patients with different hemodynamic findings after repair of tetralogy of Fallot. Am Heart $J$ 1987;113:767-72.

4 Edwards WD, Agaraval KC, Feldt RH, Danielson GK, Puga FJ. Surgical pathology of obstructed right sided porcine valved extracardiac conduit. Arch Pathol Lab Med 1983;107:400-5.

5 Fontan F, Choussat A, Devielle C, Doutremepuich C, Coupillaud J, Vosa C. Aortic valve homografts in the surgical treatment of complex cardiac malformations. $J$ Thorac Cardiothorac Surg 1984;87:649-57.

6 Kirklin JW, Blackstone EH, Shimazaki Y, Pacifico AD Kirklin JK, Bargeron LM. Survival, functional status and reoperation after repair of Tetralogy of Fallot with pulreoperation after repair of Tetralogy of Fallot with pul-
monary atresia. J Thorac Cardiovasc Surg 1988;96:102-6.

monary atresia. J Thorac Cardiovasc Surg 1988;96:102-6.
7 Olin CL, Ritter DG, McGoon DC, Wallace RB, Danielson GK. Pulmonary atresia: Surgical considerations and results in 103 patients undergoing definitive repair. Circulation 1976;54:1135-40.

8 Reid KG, Godman M, Burns J. Truncus arteriosus: successful surgical correction without the use of a valved conduit. Br Heart J 1986;56:388-90.

9 Borromee L, Lecompte Y, Batisse A, Lensoine G, Vouhe P, Sakata R, Leca F, Zamini L, Neveux JY. Anatomic repair of anomalies of ventriculoarterial connection associated with ventricular septal defect. Clinical results in 50 patients with pulmonary outflow obstruction. $J$ Thorac Cardiovasc Surg 1988;95:96-102.

10 Walsh EP, Rochenmacker S, Kane JF, Hougen TJ, Lock JE Castaneda AR. Late results in patients with TOF repaired during infancy. Circulation 1988;77:1062-7. 